\title{
Exclusive Cerebellar and Leptomeningeal Metastases from Early Gastric Cancer 14 Months after Proximal Gastrectomy: An Autopsy Case Report
}

\author{
Yuta Murakami, ${ }^{1,2}$ Toru Kobayashi, ${ }^{1}$ Yu Naruse, ${ }^{1,2}$ Fumiaki Watanabe, ${ }^{3}$ Atsushi Ishino, ${ }^{4}$ Risa Kanai, ${ }^{5}$ \\ Takeshi Goto, ${ }^{1}$ and Kiyoshi Saito ${ }^{2}$
}

\begin{abstract}
We report a rare autopsy case in which the patient received gastrectomy after an endoscopic diagnosis of early gastric cancer, and had deteriorated due to exclusive metastatic cerebellar tumors identified 14 months after surgery. A 65-year-old male was diagnosed as having a 0 -Ilc-type early gastric cancer on the posterior wall of the upper stomach by gastrointestinal endoscopy in search of a cause of epigastralgia, and thus received proximal gastrectomy and pyloroplasty. Although the tumor was in the early stages and limited within the mucosal layer, adjuvant chemotherapy was started by using S-1 $80 \mathrm{mg}$ daily due to evidence of metastasis into lymph node \#3 at the lesser curvature. Evidence of both recurrence and metastases was not detected by $\mathrm{CT}$ scans of the chest, abdomen, and pelvis, and the chemotherapy was completed 12 months after surgery. However, the patient was admitted to hospital 14 months postoperatively due to dizziness and gait disturbance. Cranial MRI (Magnetic Resonance Imaging) revealed multiple tumors in the bilateral cerebellar hemispheres with additional leptomeningeal involvement. The patient died 2 weeks after admission. An autopsy revealed metastatic cerebellar tumors and leptomeningeal lesions from the early gastric cancer, and obstructive hydrocephalus due to metastatic cerebellar tumors. To our knowledge, this case is the first report of metastasis exclusive to the cerebellum and leptomeninges from early gastric cancer limited to the mucosal layer.
\end{abstract}

Keywords: early gastric cancer, exclusive brain metastases, leptomeningeal metastases, lymphogenous pathway, metastatic cerebellar tumor

${ }^{1}$ Department of Neurosurgery, Hoshi General Hospital, Koriyama, Fukushima, Japan;

${ }^{2}$ Department of Neurosurgery, Fukushima Medical University, Fukushima, Fukushima, Japan;

${ }^{3}$ Department of Surgery, Hoshi General Hospital, Koriyama, Fukushima, Japan;

${ }^{4}$ Department of Gastroenterological Medicine, Hoshi General Hospital, Koriyama, Fukushima, Japan;

${ }^{5}$ Department of Diagnostic Pathology, Fukushima Medical University, Fukushima, Fukushima, Japan

Received: July 13, 2018; Accepted: December 13, 2018 Online March 21, 2019

Copyright $₫ 2019$ by The Japan Neurosurgical Society This work is licensed under a Creative Commons AttributionNonCommercial-NoDerivatives International License.

\section{Introduction}

Gastric cancer is the fifth most common malignancy in the world ${ }^{1)}$ with high rates in East Asia, and is the third-leading cause of cancer death in Japan. ${ }^{2}$ The age-adjusted incidence rate of Japanese gastric cancer is about twice as high as that of China and Western countries. ${ }^{3)}$ According to the Brain Tumor Registry of Japan, gastric cancer as the primary tumor causing metastatic brain tumors is the fifth highest, $3.3 \%$, following lung cancer $(46.1 \%)$, breast cancer (14.5\%), colon cancer $(6.0 \%)$ and of kidney cancer $(4.2 \%){ }^{4)}$ However, the brain is not a common metastatic site of gastric cancer, occurring in only $0.16-0.69 \%$ of all gastric cancer cases. ${ }^{5-7)}$ We report an autopsy case in which the patient progressively deteriorated 14 months after proximal gastrectomy due to brain metastases from early gastric cancer.

\section{Case Report}

A 65-year-old male was diagnosed as having a 0-IIc-type early gastric cancer on the posterior wall of the upper stomach by gastrointestinal endoscopy for epigastralgia (Fig. 1A). We performed proximal gastrectomy and pyloroplasty. According to the Japanese classification of gastric carcinoma, ${ }^{8)}$ pathological diagnosis was M, Type 0-IIc, $30 \times 17 \mathrm{~mm}$, por2 sig > por1 > tub2, pT1a, ly0, v0. pN1: lymph node (LN) \#1 (0/4), LN \#2 (0/0), LN \#3 (2/5), LN \#4sa (0/0), LN \#4sb (0/0), LN \#7 (0/0). pPM0 $(20 \mathrm{~mm}), \mathrm{pDM} 0$ (26 mm) (Figs. 1B-1D). The patient received chemotherapy with S-1 $80 \mathrm{mg}$ daily because of evidence of metastasis to LN \#3 at the lesser curvature. During this 12-month period, he was systemically followed once every 2 months, and no abnormalities were noted in tests including tumor marker and CT (computed tomography) examination. However, 14 months postoperatively, the patient presented with dizziness and gait disturbance, and he had a Karnofsky Performance Scale (KPS) score of 50. Brain MRI (Magnetic Resonance Imaging) revealed multiple tumors in the bilateral cerebellar hemispheres, with leptomeningeal involvement. Laboratory examination showed that complete blood count, blood biochemical values, and most tumor markers were within normal ranges, but revealed a mildly elevated serum carbohydrate antigen 19-9 level at $58.6 \mathrm{U} / \mathrm{ml}$ (normal level, $<37.0 \mathrm{U} / \mathrm{ml}$ ).

Brain MRI revealed numerous tumors in the bilateral cerebellar hemispheres without mass effect or perifocal edema. The tumors were hypointense on $\mathrm{T}_{1}$ weighted-images (WI), hyperintense on $\mathrm{T}_{2} \mathrm{WI}$. Gadolinium-enhanced $\mathrm{T}_{1} \mathrm{WI}$ showed 
enhancement of the tumors and revealed leptomeningeal metastases (LM) through the cerebellar folia. Considering that the patient had received gastric cancer surgery, the tumors were suspected of being metastatic brain tumors originating from the prior gastric cancer (Fig. 2). Scintigraphy revealed increased Gallium accumulation in the cerebellar hemisphere. The patient presented with dysarthria and disorientation on day 2 of hospitalization, and headache and nausea on day 6 . He was unable to take anything orally on day 8 , and became drowsy on day 10 . Head CT revealed obstructive hydrocephalus. His family did not want any further treatment for him and he received the best supportive care. He died on day 14 of hospitalization. An autopsy was performed on the same day.

There were no abnormalities in the remaining stomach. However, LN metastases were identified as follows: a metastasis of $5 \mathrm{~mm}$ in the left cardiac $\mathrm{LN} ; 10 \mathrm{~mm}$ in the peripancreatic node; $10 \mathrm{~mm}$ in a perihilar $\mathrm{LN}$; and $10 \mathrm{~mm}$ in the abdominal aortic LN. Some LNs were necrotic. The brain weighed $1560 \mathrm{~g}$ in the fresh state and edema was found in the entire cerebrum. Numerous nodules measuring $15-30 \mathrm{~mm}$ were located in the cerebellar hemispheres, and compressed the aqueduct and fourth ventricle (Figs. 3A and 3B). Adenocarcinoma cells were scattered in the subarachnoid space through the medulla oblongata to the whole cerebrum, and were abundant around the cerebellum (Fig. 3C). Pathological diagnosis was determined as gastric cancer that metastasized to the cerebellum and leptomeninges, caused obstructive hydrocephalus, and resulted in death of the patient.

\section{Discussion}

Metastatic brain tumors from gastric cancer are often multiple and simultaneous with metastases to other organs, exclusive metastasis to the brain is rare. ${ }^{5,7)}$ Brain metastases from gastric cancer are often presented in the cerebrum, whereas exclusive cerebellar metastases are rare. ${ }^{910)}$ Most of
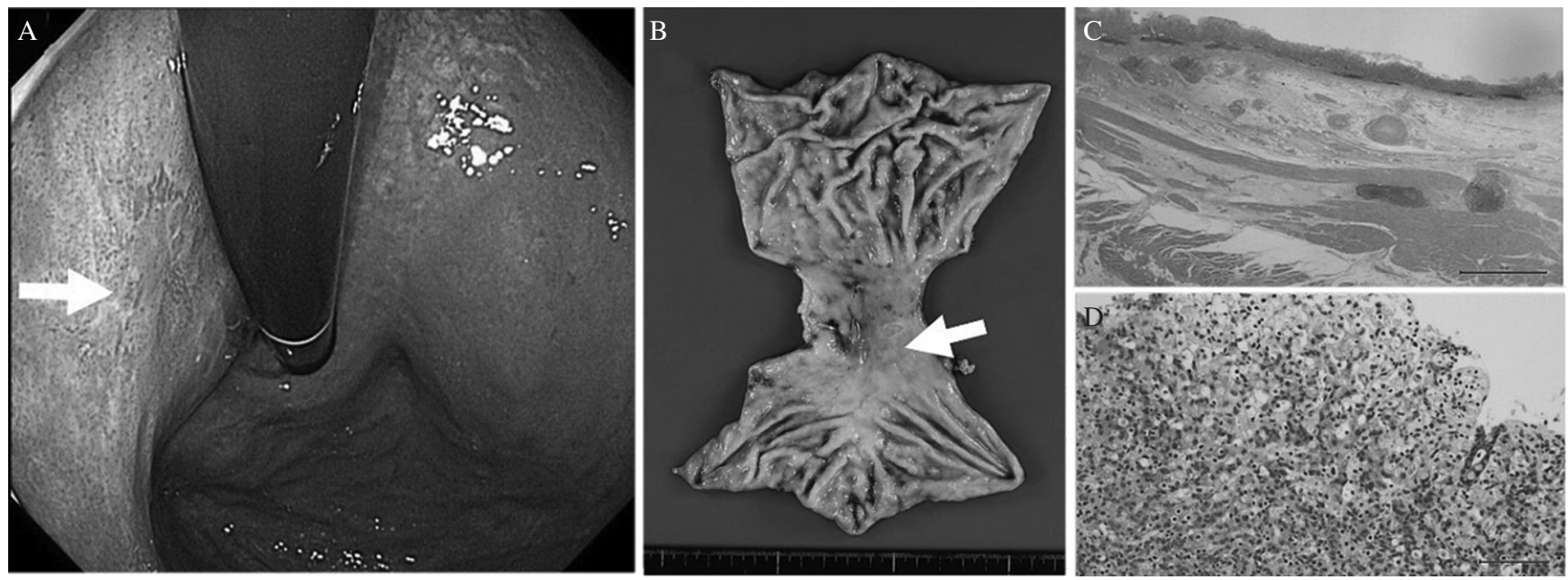

Fig. 1 A 0-IIc-type early gastric cancer on the posterior wall of the upper stomach (endoscopical findings; A, arrow, and Specimen; B, arrow) limited to the mucosal layer without lymphovascular invasion ( $\mathrm{C}$, hematoxylin-eosin stain, original magnification $12.5 \times$, scale bar was $2 \mathrm{~mm}$ ). Tumor mainly consisted of poor differentiated adenocarcinoma and signet-ring cell carcinoma (D, hematoxylin-eosin stain, original magnification 200×, scale bar was $100 \mu \mathrm{m})$. Tumor cells are positive for both CK 7 and CK 20.
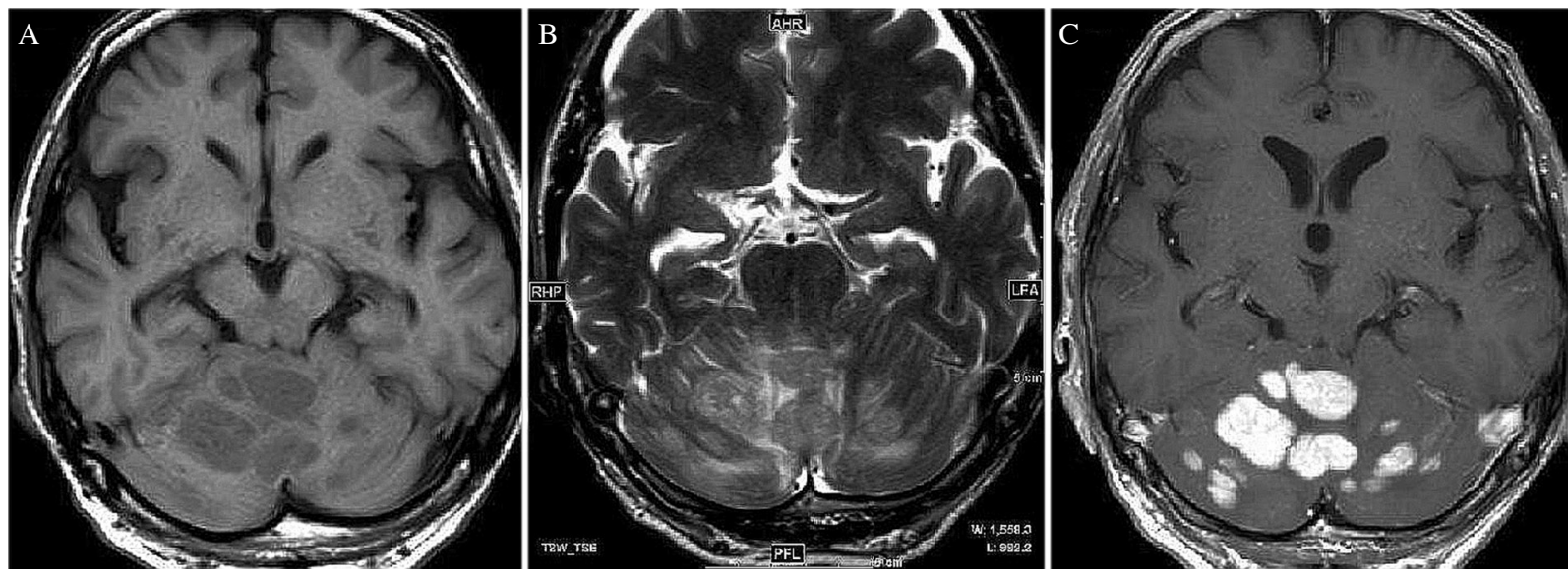

Fig. 2 Cranial MRI revealed multiple nodules involving the bilateral cerebellar hemispheres, which were hypointense on $T_{1} W I$ (A), hyperintense on $\mathrm{T}_{2} \mathrm{WI}(\mathrm{B})$, and the tumors showed enhancement on gadolinium-enhanced $\mathrm{T}_{1} \mathrm{WI}$ with leptomeningeal metastases through the cerebellar folia (C). 

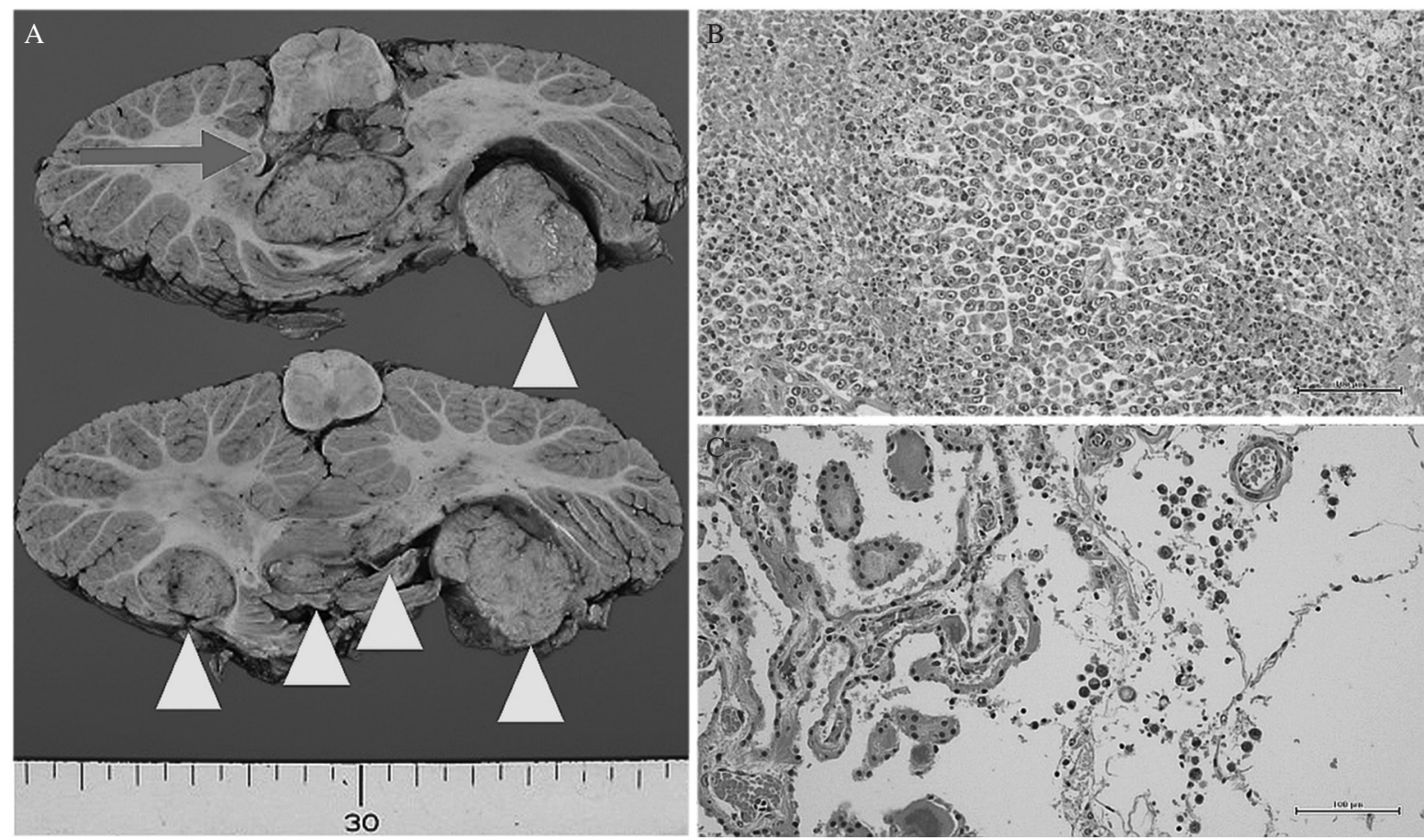

Fig. 3 Numerous nodules measuring 15-30 mm were located in the cerebellar hemisphere (A, arrow head), and compressed aqueduct and fourth ventricle (A, arrow). Microscopic finding revealed that the tumor mainly consisted of poor differentiated adenocarcinoma (B, hematoxylin-eosin stain, original magnification $200 \times$, scale bar was $100 \mu \mathrm{m}$ ). There were leptomeningeal metastases that adenocarcinoma cells were scattered in the subarachnoid space through the medulla oblongata to the whole cerebrum, and were abundant around the cerebellum (C, hematoxylin-eosin stain, original magnification $200 \times$, scale bar was $100 \mu \mathrm{m}$ ).

the brain metastases from gastric cancer are detected at an advanced stage, ${ }^{5)}$ and result in poor prognosis with a median overall survival (OS) of 2.0-9.1 months., ${ }^{4,5,9,11)}$ Regarding early gastric cancer, it is defined as invasive gastric cancer that invades no more deeply than the submucosa, regardless of LN metastases. ${ }^{8)}$ To the best of our knowledge, there have only been a few reports of exclusive brain metastases from early gastric cancer, ${ }^{9)}$ and there are no prior reports of exclusive cerebellar metastases from early gastric cancer. In the present case, we clinically diagnosed the patient as having exclusive metastatic cerebellar tumors from gastric cancer without other metastasis. Although LN metastases were identified by autopsy, scintigraphy had been revealed increased Gallium accumulation only in the cerebellar hemisphere when metastatic cerebellar tumors were detected.

Table 1 shows the clinical characteristics of case with exclusive cerebral and/or cerebellar metastases from gastric cancer reported in Japan., ${ }^{9,12-16)}$ We reviewed only Japanese gastric cancer cases because of the following reasons: abundant clinical data are available due to high incidence rate of gastric cancer in Japanese; gastric cancer is histologically classified according to the Japanese Classification of Gastric Carcinoma $^{8)}$; and the Japanese people have relatively high genetic homogeneity. ${ }^{17)}$ To the best of our knowledge, there have been 28 cases $[23$ males and 5 females, median age 68 (ranging between 30 and 83 ) years old] including the present case, from 1989 to 2017. The present case is the only one in which an autopsy was performed. The most common histological type was tubular adenocarcinoma: differentiated adenocarcinoma in six patients; moderately differentiated carcinoma in six patients; and poorly differentiated adenocarcinoma in eight patients. The metastatic sites were: cerebrum only in 14 patients, cerebellum only in 12 patients, and both the cerebrum and cerebellum in one patient. Regarding the number of metastatic lesions, 23 patients had single lesions, and five patients had multiple lesions. The median interval between the initial surgery and diagnosis of brain metastases was 10 months. The median OS was 6.5 months after brain metastases diagnosis in 27 patients whose survival time was known. Most gastric cancer depths were deeper than subserosa, and limited to submucosa in one case, and to mucosa in one case (the present case). Only the present case had coexistence of LM and parenchymal metastases, where it was difficult to identify which metastases occurred earlier. Regarding the other cases, there might have been coexistence of metastasis; however, no autopsy was performed. Although both Nomura et al. ${ }^{18)}$ and Sakurai et al. ${ }^{19)}$ reported a case of brain metastasis from early gastric cancer limited to the mucosal layer, these cases are not included in Table 1 since the cancer simultaneously metastasized to the brain and liver.

There are autopsy case reports in which it was difficult to clinically diagnose LM from gastric cancer. ${ }^{20,21)}$ Breast cancer, lung cancer, and melanoma are the most common primary tumors resulting in LM. ${ }^{22)}$ Most of the brain metastases from gastric cancers tend to be presented with leptomeningeal metastases. ${ }^{12)}$ In Japan, there are many reports of leptomeningeal metastases from gastric cancer due to the high incidence 
Table 1 Characteristics of patients with exclusive brain metastases from gastric cancer in Japan

\begin{tabular}{|c|c|c|}
\hline \multicolumn{2}{|l|}{ Characteristics } & No. \\
\hline \multicolumn{2}{|l|}{ Patients } & 28 \\
\hline Sex & Male:female & $23: 5$ \\
\hline Age & mean (min-max) & $68(30-83)$ \\
\hline \multirow{8}{*}{$\begin{array}{l}\text { Histological type } \\
\text { of gastric cancer }\end{array}$} & Papillary (pap) & 2 \\
\hline & Well differentiated (tub1) & 6 \\
\hline & Moderately differentiated (tub2) & 6 \\
\hline & Poorly differentiated (por) & 8 \\
\hline & Mucinous (muc) & 2 \\
\hline & Undifferentiated & 1 \\
\hline & Squamous cell carcinoma & 1 \\
\hline & Data not known & 2 \\
\hline \multirow{6}{*}{$\begin{array}{l}\text { Depth of gastric } \\
\text { tumor invasion }\end{array}$} & Mucosa (m) & 1 \\
\hline & Submucosa (sm) & 1 \\
\hline & Subserosa (SS) & 7 \\
\hline & Serosa exposed (SE) & 8 \\
\hline & Serosa infiltrating (SI) & 4 \\
\hline & Data not known & 7 \\
\hline \multirow{4}{*}{$\begin{array}{l}\text { Location of brain } \\
\text { metastases }\end{array}$} & Cerebrum & 14 \\
\hline & Cerebellum & 12 \\
\hline & Both cerebrum and cerebellum & 1 \\
\hline & Choroid plexus & 1 \\
\hline \multirow{2}{*}{$\begin{array}{l}\text { The number of } \\
\text { brain metastases }\end{array}$} & Single & 23 \\
\hline & Multiple & 5 \\
\hline \multirow{3}{*}{$\begin{array}{l}\text { Coexistence of } \\
\text { leptomeningeal } \\
\text { metastases }\end{array}$} & Yes & 1 \\
\hline & No & 22 \\
\hline & Data not known & 5 \\
\hline \multirow{4}{*}{$\begin{array}{l}\text { Time interval } \\
\text { between treatment } \\
\text { of primary tumor } \\
\text { and brain } \\
\text { metastases (months) }\end{array}$} & Mean (min-max) & $10(0-132)$ \\
\hline & $<12$ & 15 \\
\hline & $12<,<24$ & 7 \\
\hline & $<24$ & 6 \\
\hline \multirow{5}{*}{$\begin{array}{l}\text { Survival time after } \\
\text { diagnosis of brain } \\
\text { metastases } \\
\text { (months) }\end{array}$} & Dead & 14 \\
\hline & Mean (min-max) & $6.5(0.5-85)$ \\
\hline & Alive & 13 \\
\hline & Mean (min-max) & $28(2-120)$ \\
\hline & Data not known & 1 \\
\hline \multirow{7}{*}{$\begin{array}{l}\text { Treatment after } \\
\text { diagnosis of brain } \\
\text { metastases }\end{array}$} & Surgery & 10 \\
\hline & Surgery + radiotherapy & 7 \\
\hline & Surgery + chemotherapy & 1 \\
\hline & Surgery + radiotherapy + chemotherapy & 2 \\
\hline & Radiotherapy & 3 \\
\hline & Radiotherapy + chemotherapy & 2 \\
\hline & Best supportive care & 3 \\
\hline
\end{tabular}

of gastric cancer compared with Western countries. ${ }^{23,24)}$ Oh et al. ${ }^{25)}$ reported that $32(59.3 \%)$ out of 54 gastric cancer patients initially presented with metastatic gastric cancer without LM which then progressed to LM; however, further studies are required in a larger study population.

Recursive partitioning analysis (RPA) is a useful prognostic method for evaluating patients with metastatic brain tumors by classifying them into three groups depending on KPS (i.e., primary tumor status, presence of extracranial system metastases, and age $\mathrm{e}^{26)}$ ). Recent studies in a series of metastatic brain tumors from gastric cancer reported that the median OS was 3.5 months in RPA class 2 and 1.25-3.0 months in RPA class $3 .^{27,28)}$ Most reports in Table 1 did not describe the RPA classification and the patients had a better prognosis than those with metastatic brain tumors with multiple organ metastases. The effectiveness of radiotherapy for metastatic brain tumors has been reported in recent years; however, the prognosis is generally poor for cases with multiple metastases. ${ }^{29,30)}$ Stereotactic radiosurgery would be possible if the number of metastatic lesions was $1-3,{ }^{31)}$ or even within $10 .^{32)}$ To our knowledge, treatment outcomes of radiotherapy for metastatic brain tumors from gastric cancer have not been clearly compiled. Generally, multiple or complicated LM cases have poor prognosis. While LM from early gastric cancer is rare, advanced gastric cancer could metastasize to the leptomeninges or brain parenchyma. ${ }^{6,27)}$ The prognosis of patients with LM associated with solid tumors is poor, and the median OS is 2-3 months. ${ }^{33-35)}$ The present case had a poor prognosis due to multiple metastases to the cerebellum, complicating LM, KPS 50 and RPA class 3.

Many authors have speculated the following three routes of metastases to the cerebrum: (i) the portal venous system via the liver and lungs ${ }^{36}$; (ii) from the LNs surrounding the primary focus into the spinal subarachnoid space via nerve $\operatorname{roots}^{37,38)}$; and (iii) via the vertebral vein directly to the brain, without passing through the liver or lungs. ${ }^{39)}$ Metastatic brain tumors and LM from gastric cancer would metastasize through lymphatic routes. The third route is considered most likely for cerebellar metastases. ${ }^{39)}$ The vertebral venous systems via the transverse sinus have many anastomoses with not only the internal jugular venous system but also the cerebellar venous system. ${ }^{39)}$ Tumor cells flowing backward in the vertebral venous system are speculated to be caught by the nearby cerebellar venous systems, which is close to the tumor cells. However, in the present case, brain metastases were considered not to be hematogenous but lymphogenous because there were multiple LN metastases and LM from the medulla oblongata to the cerebrum. There are two lymphogenous pathways: (a) a pathway from the stomach to the retroperitoneal LNs, entering the subarachnoid space at the spinal level, ascending the spinal subarachnoid space and reaching the cerebellum; and (b) a pathway from the stomach that leads directly to the lymph duct of the dura mater and reaches the cerebellum through the subarachnoid space at the cerebellar level. In pathway (a), the metastasis of gastric cancer cells to the cerebellum ascending into the spinal subarachnoid space could be explained by the bulk flow theor $\mathrm{y}^{40)}$ or a diffusion phenomenon. According to the 
cerebrospinal fluid (CSF) bulk flow theory, CSF is produced mainly at the intraventricular choroid plexus and, after flowing through the subarachnoid space, is absorbed into veins or lymphatic vessels. ${ }^{40)}$ However, previous studies using the MRI Time-Spatial Inversion Pulse method suggested that CSF does not flow in one direction based on the observation of CSF flow from the third ventricle into the lateral ventricles, and no flow or pulsation of the CSF over the cerebral convexity. ${ }^{41,42)}$ As the CSF does not ascend into the intracranial space, tumor cells diffuse through the subarachnoid space and reach the cerebellum. On the other hand, (b) is a possible pathway, reaching the cerebellum because of the discovery that lymphatic vessels exist in the central nervous system. ${ }^{43)}$ In the present case, there were adenocarcinoma cells scattered in the subarachnoid space, and they were especially abundant around the cerebellum, although tumor cells should have been distributed equally in the subarachnoid space if they had spread from the level of the spinal cord to cerebrum. Furthermore, considering the evidence of local metastases to only LNs, it is likely that the gastric cancer cells metastasized from the stomach to the cerebellum through the lymphatic system. Lymphatic vessels in the mucosal layer of the stomach wall were found in the deepest layer of the lamina propria. ${ }^{44,45)}$ So lymphatic metastases from mucosal gastric cancer can occur as in the present case.

We administered S-1, a combination drug with tegafur (FT), 5-chloro-2,4-dihydroxypyridine, and potassium oxonate (Oxo), as postoperative adjuvant therapy. Our autopsy findings showed that $\mathrm{S}-1$ was effective against LN metastases because some LNs were necrotic and LN metastases did not accumulate Gallium. FT could pass the blood-brain barrier $(\mathrm{BBB})^{46)}$; however, there is no data on whether S-1 itself can pass the BBB or not. Exclusive cerebellar metastases and LM may have occurred in our patient due to BBB permeability.

\section{Conflicts of Interest Disclosure}

The authors have no conflicts of interest to declare.

\section{References}

1) Ferlay J, Soerjomataram I, Dikshit R, et al.: Cancer incidence and mortality worldwide: sources, methods and major patterns in GLOBOCAN 2012. Int J Cancer 136: E359-E386, 2015

2) Shitara K, Chin K, Yoshikawa T, et al.: Phase II study of adjuvant chemotherapy of S-1 plus oxaliplatin for patients with stage III gastric cancer after D2 gastrectomy. Gastric Cancer 20: 175-181, 2017

3) Sobue T, Saika K: Cancer incidence and mortality in the world. J Clin Exp Med 241: 307-312, 2012 (Japanese).

4) Committee of Brain Tumor Registry of Japan: Brain Tumor Registry of Japan (2005-2008). Neurol Med Chir (Tokyo) 57: 9-102, 2017

5) York JE, Stringer J, Ajani JA, Wildrick DM, Gokaslan ZL: Gastric cancer and metastasis to the brain. Ann Surg Oncol 6: 771-776, 1999

6) Kim M: Intracranial involvement by metastatic advanced gastric carcinoma. J Neurooncol 43: 59-62, 1999

7) Kasakura Y, Fujii M, Mochizuki F, Suzuki T, Takahashi T: Clinicopathological study of brain metastasis in gastric cancer patients. Surg Today 30: 485-490, 2000

8) Japanese Gastric Cancer Association: Japanese classification of gastric carcinoma: 3rd English edition. Gastric Cancer 14: 101-112, 2011

9) Matsubara T, Yoshizawa Y, Sasaya S, et al.: A long survival case of metachronous cerebellar metastasis that was caused by gastric cancer. Jpn J Gastroenterol Surg 41: 76-81, 2008 (Japanese).
10) Kanazawa Y, Fujita I, Kakinuma D, et al.: Five-year survival after surgical removal and gamma knife stereotactic radiosurgery for a cerebellar metastasis from an esophagogastric junction cancer: a case report and literature review. In Vivo 31: 1209-1214, 2017

11) Go PH, Klaassen Z, Meadows MC, Chamberlain RS: Gastrointestinal cancer and brain metastasis: a rare and ominous sign. Cancer 117: 3630-3640, 2011

12) Sugenoya $Y$, Saiki H, Araki T, Narita K: A case of cerebellar metastasis that was considered to be caused by gastric cancer. Jpn J Gastroenterol Surg 34: 100-104, 2001 (Japanese).

13) Kahiszuka H, Yamada Y, Tatsumi M, Nakajima Y: A case of gastric cancer that cerebral metastasis was primary symptom. Nihon Gekakei Rengo Gakkaishi 29: 234-238, 2004 (Japanese).

14) Mizumatsu S, Nishimura T, Sakai K, Goto M, Sugatani H, Higashi T: A case of brain metastasis from gastric cancer involving bilateral middle cerebellar peduncles. No Shinkei Geka 34: 955-960, 2006 (Japanese).

15) Tamura S, Takeno A, Miki H, et al.: Clinical outcomes in patients with brain metastasis from gastric cancer. Gan To Kagaku Ryoho 38: 20932096, 2011 (Japanese).

16) Kawano S, Kobayashi A, Shibasaki H, Kinoshita T, Saito N: A case of long-term survival with a solitary cereberellar metastasis from gastric cancer. Nihon Rinsho Geka Gakkai Zasshi 76: 757-761, 2015 (Japanese).

17) Haga H, Yamada R, Ohnishi Y, Nakamura Y, Tanaka T: Gene-based SNP discovery as part of the Japanese Millennium Genome Project: identification of 190,562 genetic variations in the human genome. Single-nucleotide polymorphism. J Hum Genet 47: 605-610, 2002.

18) Sakurai K, Muguruma K, Murata A, et al.: Early gastric cancer with suspected brain metastasis arising eight years after curative resection: a case report. BMC Res Notes 7: 818, 2014

19) Nomura T, Yoshikawa $T$, Kato $H$, et al.: Early gastric cancer manifested as brain metastasis: report of a case. Surg Today 27: 334-336, 1997

20) Grove A: Meningeal carcinomatosis from a clinically undiagnosed early gastric cancer. Pathol Res Pract 187: 341-345; discussion 345-347, 1991

21) Braeuninger S, Mawrin C, Malfertheiner P, et al.: Gastric adenocarcinoma with leptomeningeal carcinomatosis as the presenting manifestation: an autopsy case report. Eur J Gastroenterol Hepatol 17: 577-579, 2005

22) Lee SJ, Lee JI, Nam DH, et al.: Leptomeningeal carcinomatosis in non-small-cell lung cancer patients: impact on survival and correlated prognostic factors. J Thorac Oncol 8: 185-191, 2013

23) Takakura K, Sano K, Hojo S, Hirano A (eds): Metastatic Tumors of the Central Nervous System. Tokyo, Igaku-shoin, 1982

24) Waki F, Ando M, Takashima A, et al.: Prognostic factors and clinical outcomes in patients with leptomeningeal metastasis from solid tumors. J Neurooncol 93: 205-212, 2009

25) Oh SY, Lee SJ, Lee J, et al.: Gastric leptomeningeal carcinomatosis: multi-center retrospective analysis of 54 cases. World J Gastroenterol 15: 5086-5090, 2009

26) Gaspar L, Scott C, Rotman M, et al.: Recursive partitioning analysis (RPA) of prognostic factors in three Radiation Therapy Oncology Group (RTOG) brain metastases trials. Int J Radiat Oncol Biol Phys 37: 745-751, 1997

27) Park YS, Chang JH, Chang JW, Park YG: The efficacy of gamma knife radiosurgery for advanced gastric cancer with brain metastases. J Neurooncol 103: 513-521, 2011

28) Mizokami Y, Mitsuya K, Hayashi N, et al.: Metastatic brain tumors from gastrointestinal cancer: an analysis of patient background and treatment results. No Shinkei Geka 41: 669-677, 2013 (Japanese).

29) Kihlström L, Karlsson B, Lindquist C: Gamma Knife surgery for cerebral metastases. Implications for survival based on 16 years experience. Stereotact Funct Neurosurg 61: 45-50, 1993

30) Sheehan JP, Yen CP, Nguyen J, Rainey JA, Dassoulas K, Schlesinger DJ: Timing and risk factors for new brain metastasis formation in patients initially treated only with Gamma Knife surgery. Clinical article. J Neurosurg 114: 763-768, 2011

31) Brown PD, Jaeckle K, Ballman KV, et al.: Effect of radiosurgery alone vs radiosurgery with whole brain radiation therapy on cognitive function in patients with 1 to 3 brain metastases: a randomized clinical trial. JAMA 316: 401-409, 2016

32) Li J, Brown PD: The diminishing role of whole-brain radiation therapy in the treatment of brain metastases. JAMA Oncol 3: 1023-1024, 2017

33) Glantz MJ, Jaeckle KA, Chamberlain MC, et al.: A randomized controlled trial comparing intrathecal sustained-release cytarabine (DepoCyt) to 
intrathecal methotrexate in patients with neoplastic meningitis from solid tumors. Clin Cancer Res 5: 3394-3402, 1999

34) Tomita H, Yasui H, Boku N, et al.: Leptomeningeal carcinomatosis associated with gastric cancer. Int J Clin Oncol 17: 361-366, 2012

35) Murakami Y, Ichikawa M, Bakhit M, et al.: Palliative shunt surgery for patients with leptomeningeal metastasis. Clin Neurol Neurosurg 168: $175-178,2018$

36) Konno Y: Clinicopathological study of intracranial metastatic tumors. Byori To Rinsho 1: 942-954, 1983 (Japanese).

37) Chason JL, Walker FB, Landers JW: Metastatic carcinoma in the central nervous system and dorsal root ganglia. A prospective autopsy study. Cancer 16: 781-787, 1963

38) Kokkoris CP: Leptomeningeal carcinomatosis. How does cancer reach the pia-arachnoid? Cancer 51: 154-160, 1983

39) Batson OV: The function of the vertebral veins and their role in the spread of metastases. Ann Surg 112: 138-149, 1940

40) Oresković D, Klarica M: The formation of cerebrospinal fluid: nearly a hundred years of interpretations and misinterpretations. Brain Res Rev 64: 241-262, 2010
41) Yamada S, Miyazaki M, Kanazawa H, et al.: Visualization of cerebrospinal fluid movement with spin labeling at MR imaging: preliminary results in normal and pathophysiologic conditions. Radiology 249: 644-652, 2008

42) Yamada S: Cerebrospinal fluid physiology: visualization of cerebrospinal fluid dynamics using the magnetic resonance imaging Time-Spatial Inversion Pulse method. Croat Med J 55: 337-346, 2014

43) Louveau A, Smirnov I, Keyes TJ, et al.: Structural and functional features of central nervous system lymphatic vessels. Nature 523: 337-341, 2015

44) Sako A, Kitayama J, Ishikawa M, Yamashita H, Nagawa H: Impact of immunohistochemically identified lymphatic invasion on nodal metastasis in early gastric cancer. Gastric Cancer 9: 295-302, 2006

45) Kim YI, Lee JH, Kook MC, et al.: Lymph node metastasis risk according to the depth of invasion in early gastric cancers confined to the mucosal layer. Gastric Cancer 19: 860-868, 2016

46) Fujita H, Ogawa K, Akimoto H, et al.: Distribution of FT-207 and its active substances into the brain and cerebrospinal fluid. Jpn J Cancer Chemother (Tokyo) 3: 551, 1976 (Japanese). 